our study indicate that it is unlikely that inhibitors of calcineurin activation can reduce cardiac hypertrophy induced by hemodynamic overload. It remains possible that calcineurin functions as a modulator of cardiac hypertrophy arising from less-common etiologies, such as endocrine or genetic disorders. However, ventricular hypertrophy induced by pressure overload, commonly associated with hypertension or valvular disease in humans, may involve the activation of other molecular pathways.

ZHENGYU LUO ${ }^{1}$, KUO-GI SHYU
ANTONIO GUALBERTO
ANT
\& KENNETH W ALSH
${ }^{1}$ Division of Cardiovascular Research
St. Elizabeth's M edical Center and
Tufts University School of Medicine
736 Cambridge Street
Boston, MA 02135, USA
${ }^{2}$ Department of Physiology
Case W estern Reserve University

School of Medicine

10900 Euclid Avenue

Cleveland, OH 44106, USA

Correspondence should be addressed to K.W .; email: kwalsh@opal.tufts.edu

1. Schwartz, K. \& Mercadier, J.J. Molecular and cellular biology of heart failure. Curr. Opin. Cardiol. 11, 227-236 (1996)

2. Rao, A., Luo, C. \& Hogan, P.G. Transcription factors of the NFAT family: regulation and function. Annu. Rev. Immunol. 15, 707-747 (1997).

3. Molkentin, J.D. et al. A calcineurin-dependent transcriptional pathway for cardiac hypertrophy. Cell 93, 215-228 (1998).

4. Hasegawa, K., Lee, S.J., Jobe, S.M., Markham, B.E. $\&$ Kitsis, R.N. cis-acting sequences that mediate induction of $\beta$-myosin heavy chain gene expression during left ventricular hypertrophy due to aortic constriction. Circulation 96, 3943-3953 (1997).

5. Radermacher, J. et al. Pronounced renal vasoconstriction and systemic hypertension in renal transplant patients treated with cyclosporin A versus FK 506. Transpl. Int. 11, 3-10 (1998).

6. McKoy, R.C. et al. Left ventricular hypertrophy in cyclosporine-induced systemic hypertension after cardiac transplantation. Am. J. Cardiol. 62, 1140-1142 (1988).

7. Sadeghi, A.M. et al. Cyclosporine increases rat heart weight in heterotopic transplants. Curr. Surg. 44, 51-52 (1987).

\title{
No evidence for MUC 1-induced apoptosis
}

To the editor-We note the paper of Agrawal et al. ${ }^{1}$ which, in contradiction to our earlier report (Gimmi et al., ref. 2), could not find evidence of MUC 1-induced apoptosis of $\mathrm{T}$ cells.

Prior to the Agrawal et al. publication, one of the authors of Gimmi et al. reported that he was unable to reproduce the apoptosis finding and indicated that a colleague in another institution had also failed to reproduce that finding. In view of the significance of this disagreement, Dana-Farber Cancer Institute appointed an internal committee of experienced immunologists to examine our paper and define an appropriate action. The committee recommended that the Nadler laboratory repeat the apoptosis experiments that it had previously performed. These new experiments were carefully supervised and reviewed, and they showed that neither purified MUC 1 nor stable transfectants expressing MUC 1 cDNA caused detectable apoptosis. Hence we agree with Agrawal et al. that apoptosis is not involved in MUC 1 induced T cell dysfunction.

We do not know why our previously reported results were wrong and regret the confusion that we have caused in the scientific literature. The role of MUC 1 in cancer cell biology remains obscure.

VASSILIKI A. BOUSSIOTIS ${ }^{1}$, GORdON J. FREEMAN ${ }^{1}$,

John G. Gribben ${ }^{1,}$ Daniel F. Hayes ${ }^{2} \&$ LeE M. Nadler $^{1}$

${ }^{1}$ Dana Farber Cancer Institute

Harvard Medical School

44 Binney Rd

Boston, MA 02115

${ }^{2}$ Breast Cancer Program

Lombardi Cancer Research Center

Georgetown University M edical Center

3970 Reservior Road NW

W ashington, DC 20007

1. Agrawal, B, Krantz, M.J., Reddish, M.A. \& Longenecker, B.M. Cancer-associated MUC1 mucin inhibits human T-cell proliferation, which is reversible by IL-2. Nature Med. 4, 43-49 (1998).

2. Gimmi, C.D. et al. Breast cancer-associated antigen, DF3/MUC1, induces apoptosis of activated human T cells. Nature Med. 2, 1367-1370 (1996). 